\title{
PERSPECTIVAS DEL DERECHO INDIVIDUAL DEL TRABAJO
}

\author{
Emilio Morgado Valenzuela* \\ Universidad de Chile
}

\section{INTRODUCCIÓN}

La Real Academia Española, en su Diccionario de la Lengua, asigna siete significados a la voz "perspectiva". Para los efectos de esta exposición, perspectiva es entendida como el punto de vista desde el cual se analizan las posibilidades para un futuro, considerando tanto la visión de lo presente como la visión del pasado.

Ello nos conduce a visualizar la evolución del derecho individual del trabajo distinguiendo tres etapas: el pasado, el presente y el futuro previsible. Teniendo presente los muy amplios y variados contenidos del derecho individual del trabajo, focalizo mi análisis en cuatro temas relevantes: (i) la existencia y características de la relación de trabajo; (ii) el tiempo de trabajo y su distribución; (iii) la seguridad y salud en el trabajo, y (iv) la terminación de la relación de trabajo.

\section{EL PASADO (DESDE LOS INICIOS DE LA REPÚBLICA HASTA EL 10 DE SEPTIEMBRE DE 1973)}

La visión del pasado torna necesario distinguir dos períodos: (i) desde los orígenes hasta el 11 de septiembre de 1973, y (ii) desde el 11 de septiembre de 1973 hasta el 10 de marzo de 1990.

\subsection{Primer Período: La Construcción Proteccionista (Desde los orígenes has- TA EL IO DE SEPTIEMBRE DE I973)}

Desde los inicios republicanos se adoptaron normas que contenían algunas referencias a ciertos aspectos concernientes al trabajo que desarrollaban profesores, médicos, funcionarios gubernamentales, personal de las fuerzas armadas, mineros, cuidadores, vigilantes, marinos, zapateros, carteros, mensajeros, y los laborantes en el comercio, las obras públicas, la construcción, el ferrocarril. La esclavitud fue abolida mediante normas dictadas entre 1813 y 1841.

La adopción del Código Civil (1855) y sus normas inspiradas en la locatio conducto rei, locatio conducto operis y locatio conducto operarum, y la posterior adopción del Código de Comercio (1865) -y sus normas acerca de la prestación de servicios inmateriales en el comercio- dieron

\footnotetext{
* Abogado (Universidad de Chile). Doctor Honoris Causa (Université de Bordeaux, Francia). Vicepresidente de la Sociedad Internacional de Derecho del Trabajo y Seguridad Social. Consultor nacional e internacional. Miembro del Panel Arbitral de la Cláusula Laboral del Tratado de Libre Comercio de Estados Unidos y Chile. Miembro no Nacional de la Cláusula Laboral del Tratado de Libre Comercio de Estados Unidos, América Central y República Dominicana. Ex Presidente y Presidente de Honor de la Academia Iberoamericana de Derecho del Trabajo y de la Seguridad Social. Ex Presidente y Presidente Honorario de la Sociedad Chilena de Derecho del Trabajo y de la Seguridad Social. Ex funcionario y Director Regional Adjunto de la Oficina de la OIT para América Latina y el Caribe. Contacto: mormauemilio@gmail.com
} 
Emilio Morgado Valenzuela / Perspectivas del derecho individual del trabajo

cabida a la aplicación de sus regulaciones en las correspondientes modalidades de trabajo humano entonces existentes.

El principio proteccionista comienza a manifestarse con la adopción del Código de Procedimiento Civil (1903), y sus normas referidas a la inembargabilidad de las remuneraciones, pensiones y herramientas de los artesanos, artistas y obreros, necesarias para el desempeño de sus funciones. Luego se adoptaron leyes sobre la vivienda obrera (1906), el descanso dominical no remunerado (1907), la obligación de habilitar sillas para el descanso de los trabajadores en los establecimientos comerciales (1914), los accidentes del trabajo (1916), las salas cuna (1917).

Las variadas manifestaciones de la llamada "cuestión social" y los graves conflictos colectivos de trabajo -y sus sangrientas consecuencias- así como las denuncias y proposiciones de soluciones formuladas por líderes de las organizaciones de trabajadores y por intelectuales, académicos y políticos, dieron lugar a la designación de sendas comisiones presidenciales en 1904, 1913 y 1917, encargadas de formular proposiciones encaminadas a prevenir y solucionar los conflictos laborales y sus efectos en el orden público.

De otra parte, en 1906 se estableció una Comisión Especial de Legislación del Trabajo en la Cámara de Diputados (que pasó a ser de carácter permanente en 1921), en tanto que en 1920 el Senado estableció una Comisión Especial de Asuntos Laborales. En 1907 se creó la Oficina del Trabajo, como dependencia del entonces Ministerio de Industria y Obras Públicas.

En 1919, un grupo de siete Senadores del Partido Conservador, encabezados por Juan E. Concha (Senador y Profesor de la Universidad Católica), presentaron un proyecto de ley referido a condiciones de trabajo, sindicatos legales y conflictos colectivos.

Durante la campaña presidencial de 1929, el Senador Arturo Alessandri Palma, candidato de la Alianza Liberal, puso de relieve la necesidad de contar con una apropiada legislación del trabajo. Ya elegido Presidente, en junio de 1921 presentó un proyecto de Código del Trabajo, elaborado por Moisés Poblete Troncoso, Director de la Oficina del Trabajo ${ }^{1}$. El proyecto de Código se inspiraba en los principios de justicia social y de legislación protectora incorporados en el Tratado de Versalles, y en los primeros Convenios Internacionales adoptados por la Organización Internacional del Trabajo, creada en 1919.

En lo concerniente al Derecho Individual del Trabajo, en el proyecto de Código se regulaban materias tales como el contrato de trabajo, la limitación del tiempo diario y semanal de trabajo, la lucha contra el desempleo, el salario suficiente para asegurar buenas condiciones de vida, la protección de los trabajadores contra los accidentes del trabajo y enfermedades profesionales, la protección del trabajo de las mujeres, los niños y adolescentes, la protección de los trabajadores migrantes, la educación técnica y la formación profesional.

Hasta septiembre de 1924, el Gobierno no logró que el Congreso aprobara el proyecto de Código del Trabajo de 1921. El levantamiento militar del 5 de septiembre tuvo como una de sus demandas la adopción de legislación del trabajo. Otra demanda fue la aprobación del proyecto de ley de clases y rentas del Ejército.

De las siete leyes del trabajo aprobadas en esa ocasión, tres regulaban materias del derecho individual del trabajo:

\footnotetext{
1 Moisés Poblete Troncoso fue Profesor de Economía Social y Legislación Obrera en la Escuela de Derecho de la Universidad de Chile, en la que además desempeñó otras funciones académicas. También fue un destacado funcionario de la Oficina Internacional del Trabajo, tanto en Ginebra como en Chile.
} 
a) Ley 4053 , sobre el contrato de trabajo de los obreros.

b) Ley 4055 , sobre accidentes del trabajo y enfermedades.

c) Ley 4059 , sobre empleados del sector privado.

Esa legislación inicial fue seguida por la adopción de nuevas normas referidas a materias tales como la prohibición del trabajo nocturno en panaderías y establecimientos similares, modificaciones a las leyes $n^{\circ} 4053$ y $n^{\circ} 4959$, la ampliación del descanso dominical no remunerado a otros grupos de trabajadores, las modificaciones a la ley $n^{\circ} 4055$, y la protección de la madre trabajadora.

Con algunas modificaciones, la legislación de 1924 y la recién evocada, fueron incorporadas en el Código del Trabajo contenido en el DFL 178, del 13 de mayo de 1931, en el que además se regularon materias laborales adicionales a las ya legisladas. Conviene evocar que esas reformas legislativas tuvieron lugar en un entorno político muy convulsionado.

Desde esa fecha y hasta el 11 de septiembre de 1973, las normas del Código de 1931 fueron objeto de numerosas y variadas modificaciones legales. De ellas, sólo mencionaremos algunas de las que tuvieron mayores efectos, agrupándolas en torno a los siguientes grandes temas: (i) existencia y características de la relación de trabajo; (ii) tiempo de trabajo y su distribución; (iii) seguridad y salud en el trabajo, y (iv) terminación de la relación de trabajo.

Cabe advertir que dentro de este largo período, el entorno político se caracterizó por la existencia de una etapa inicial de ensayos institucionales, seguida por: (i) la restauración institucional habida en el nuevo período presidencial de Arturo Alessandri Palma; (ii) los gobiernos de izquierda y de centro izquierda liderados por el Partido Radical (Pedro Aguirre Cerda, Juan Antonio Ríos Morales y Gabriel González Videla); (iii) el segundo gobierno del General Carlos Ibáñez del Campo, ahora elegido democráticamente; (iv) el gobierno de centro derecha de Jorge Alessandri Rodriguez; (v) el gobierno demócratacristiano de Eduardo Frei Montalva, y (vi) el gobierno de izquierda de Salvador Allende Gossens. Sus respectivas definiciones doctrinarias y programáticas influyeron en la configuración de las correspondientes políticas laboras y sus respectivas expresiones normativas.

\section{A. Existencia y caracteristicas de la relación de trabajo}

1.- Ley 5.405 , sobre la calificación de la condición jurídica de empleado particular o de obrero, y otras materias.

2.- Ley 7.180, sobre el contrato de trabajo de los obreros.

3.- Ley 6.020: sobre el mejoramiento de las condiciones de trabajo y determinación del sueldo vital de los empleados particulares, y otras materias.

4.- Ley 6.242, sobre la condición jurídica de empleados de los choferes permanentes en hogares y en establecimientos industriales y comerciales.

5.- Ley 6.612: sobre reformas a la ley $6.020 \mathrm{y}$ otras materias.

6.- Ley 6.939, sobre las gratificaciones.

7.- Ley 7.295 , sobre condiciones de trabajo y sueldo vital de los empleados particulares, y otras materias.

8.- Ley 7.746, sobre el trabajo marítimo, portuario y fluvial y otras materias.

9.- Ley 8.067, sobre reformas referidas a los descuentos a los salario (obreros) y sueldos (empleados), para pagar cuotas a instituciones de enseñanza de cursos por correspondencia

10.-Ley 8.157, sobre vacaciones anuales. 
Emilio Morgado Valenzuela / Perspectivas del derecho individual del trabajo

11.- Ley 8.814, sobre la Junta Clasificadora de Empleados y Obreros, encargada de resolver reclamaciones acerca de la calidad jurídica de empleado u obrero asignada a un trabajador, así como determinar la existencia de una relación de trabajo.

12.-Ley 10.621 sobre los periodistas y el personal de imprentas y fotograbadores.

13.-Ley 11.237, sobre el personal docente.

14.- Ley 11.833, sobre el reconocimiento de la condición jurídica de empleados de los vendedores en carnicerías, fiambrerías y establecimientos similares.

15.-Ley 14.688, sobre modificaciones a la Ley 7.295.

16.- Ley 15.467 , sobre el reconocimiento de la condición jurídica de empleados a los torneros, matricistas y fresadores.

17.- Ley 15.944, sobre el reconocimiento de la condición jurídica de empleados a los electricistas.

18.- Ley 16.425, sobre algunas condiciones de trabajo en la Gran Minería del Cobre, incluyendo el reemplazo de la palabra "obrero" por "trabajador", y otras materias.

19.-Ley 17.141, sobre el reconocimiento de la condición jurídica de empleados a ciertas categorías de trabajadores.

\section{B. Tiempo de trabajo y su distribución}

1.- Ley 5.405, jornada de los obreros y horario uniforme de apertura y cierre de establecimientos comerciales e industriales.

2.- Ley 6.812 , sobre las vacaciones.

3.- Ley 7.296, sobre las horas las horas de trabajo y de descanso de los serenos.

4.- Ley 9.128, sobre la duración del tiempo de trabajo.

5.- Ley 10.988 , sobre feriados de trabajadores marítimos, portuarios y fluviales.

6.- Ley 15.475, sobre feriado progresivo.

7.- Ley 16.311 , sobre la prohibición del trabajo nocturno y del trabajo subterráneo de mujeres, y otras materias.

8.- Ley 16.324. sobre la jornada de trabajo de los empleados bancarios.

9.- Ley 16.434, sobre la ampliación del descanso postnatal, y otras materias.

10.-Ley 16.581, sobre el tiempo de trabajo en la minería del carbón.

11.-Ley 16.676, sobre el tiempo semanal de trabajo de los radio-operadores telefónicos operadores telefónicos y probadores telefónicos, la que no debía exceder 42 horas.

\section{Seguridad y salud en el trabajo}

1.- Ley 14.996, sobre pérdida permanente de la capacidad de trabajo debido a una enfermedad profesional.

2.- Ley 16.744 , sobre accidentes del trabajo y enfermedades profesionales.

\section{Terminación de la relación de trabajo}

1.- Ley 16.455 , sobre la terminación del contrato de trabajo. 


\subsection{Segundo Período: La Demolición Desproteccionista (Desde el i i de sep-} TIEMBRE DE I973 HASTA EL IO DE MARZO DE I990)

Este período se instala y desarrolla durante la dictadura militar encabezada por el General Augusto Pinochet Ugarte (11 de septiembre de 1973 al 10 de marzo de 1990). Entre los objetivos políticos y económicos de la legislación desreguladora de la protección cabe evocar cuatro: (i) anular el poderío alcanzado por el movimiento sindical, especialmente el logrado en las décadas de los años 50 al 70; (ii) poner término a las tendencias centralizadoras en las relaciones colectivas de trabajo; (iii) flexibilizar las relaciones individuales de trabajo, y (iv) facilitar la implantación del modelo de libre mercado ilimitado basado en los postulados doctrinarios y programáticos de Milton Friedman y Friedrich von Hayek.

La demolición desreguladora se efectuó recurriendo a cuatro modalidades de flexibilización: (i) la flexibilización de facto, consiste en la no aplicación de normas legales o convencionales; (ii) la flexibilización normativa, particularmente expresada en el Decreto-Ley 2.200 (1978) y en los Decretos-Leyes constitutivos del llamado Plan Laboral (1979), (iii) la flexibilización unilateral, decidida por el empleador, conocida como ius variandi, y (iv) la flexibilización bilateral, acordada por las partes. Las dos últimas variables tienen, además, la condición de ser facultadas por ley (flexibilidad normativa delegada).

La "flexibilización heterónoma" comprendió numerosos aspectos de las relaciones individuales de trabajo, entre otras, las referidas a las remuneraciones. En esa materia, las principales transformaciones fueron: (i) la derogación de las normas sobre salarios mínimos de los obreros y sueldos vitales de los empleados; (ii) la derogación de los sistemas preexistentes para el reajuste automático de las remuneraciones teniendo presente los índices oficiales de elevación del costo de vida; (iii) el establecimiento del llamado "ingreso mínimo mensual", sin reajuste automático de su monto, y (iv) la reforma de las normas sobre gratificaciones anuales, especialmente en lo relacionado con sus montos máximos y las imputaciones de pagos ya efectuados.

La flexibilización unilateral del empleador (ius variandi) adquirió especial relevancia en los casos siguientes: (i) se autorizó al empleador para alterar la naturaleza de los servicios y el lugar donde éstos deben prestarse, siempre que las nuevas labores sean similares, que el nuevo lugar de trabajo esté ubicado en la misma localidad o ciudad y que la alteración no importe menoscabo para el trabajador; (ii) se autorizó al empleador para alterar hasta en sesenta (60) minutos la distribución convenida del tiempo de trabajo, adelantando o postergando la hora de ingreso al trabajo. Para ello deben existir circunstancian que lo justifiquen y se debe dar aviso anticipado al trabajador; (iii) se autorizó al empleador para ampliar la jornada de los dependientes de comercio hasta un máximo de diez (10) horas diarias en los períodos inmediatamente anteriores a Navidad, Fiestas Patrias u otras festividades, y (iv) se autorizó al empleador para determinar la oportunidad en que los trabajadores de la empresa, establecimiento o sección pueden hacer uso de su feriado anual.

Mediante la "flexibilización convencional", la nueva normatividad amplió el número de casos en que las normas legales pueden ser alteradas si media una convención individual o colectiva. En consecuencia, se extendió el campo en que las partes pueden disponer libremente de los derechos establecidos en la legislación. Principalmente, esta modalidad flexibilizadora se manifestó respecto de: (i) los descansos en los días domingo y de feriado legal; (ii) las gratificaciones legales, y (iii) las indemnizaciones por término de contrato. 
Emilio Morgado Valenzuela / Perspectivas del derecho individual del trabajo

Sin perjuicio de lo ya expresado respecto de la "flexibilización desreguladora de naturaleza heterónoma", cabe destacar la adopción de normas legales desprotectoras habidas en las siguientes materias: (i) la existencia y características de la relación de trabajo; (ii) el tiempo de trabajo y su distribución, (iii) la seguridad y salud en el trabajo, y (iv) la terminación de la relación de trabajo.

\section{A. Existencia y características de la relación de trabajo}

- Se aumentó el número de relaciones de trabajo excluidas -directa o indirectamente- del ámbito de aplicación de la normatividad laboral, ampliando el campo de la deslaboralización de relaciones que, en esencia, son laborales. Es así como pasó a ser mayor la conversión de trabajadores en prestadores independientes de servicios, que no perciben remuneraciones sino honorarios, que resultan marginados de la protección de sus derechos laborales a la vez que muy limitados como sujetos del eventual ejercicio de derechos colectivos como la sindicación y la negociación colectiva.

- Se estableció - para los efectos de la legislación laboral y de seguridad social- una definición de empresa que entre sus componentes conceptuales incluyó la condición de estar "dotada de una individualidad legal determinada", cuna del llamado problema del "multirut".

- Se multiplicaron las modalidades de contratación indirecta y de "triangulación" de la relación de trabajo, especialmente a través de modalidades de externalización, como la intermediación, la subcontratación, el suministro de trabajo temporal y el "outsourcing", todas ellas desarrolladas sin la existencia de normas reguladoras estatales.

- Se privilegió la contratación por plazo definido, la que dejó de ser una excepción debido a que: (i) se redujeron las condiciones exigidas para que ella tenga lugar; (ii) aumentar las condiciones exigidas para su transformación automática en contratación de plazo indefinido, y (iii) se amplió su duración máxima, que antes era de 6 meses.

- Se excluyó a los medieros y aparceros del campo de aplicación de la legislación laboral aplicable a los que trabajan en la agricultura. A la vez, se derogó la normativa anterior sobre el salario mínimo agrícola y se autorizó la existencia de remuneraciones inferiores al ingreso mínimo legal.

- Se derogó la regulación del trabajo a domicilio.

- Se estableció un marco normativo peyorativo en lo concerniente a la contratación de menores, mediante: (i) la derogación de la obligación de proporcionar tiempo libre - dentro de la jornada de trabajo- a los menores que no han cumplido con la obligación escolar, y (ii) la autorización del trabajo nocturno de menores de 16 años en los trabajos industriales que, por su naturaleza, deban continuarse de día y de noche.

- Se estableció un marco normativo peyorativo en lo concerniente a la contratación de aprendices: (i) al disponer que la remuneración de los aprendices será convenida libremente por las partes, por lo que puede ser de monto inferior al del ingreso mínimo legal, y (ii) al prohibir que sus remuneraciones sean reguladas mediante convenios o contratos colectivos o fallos arbitrales.

\section{B. Tiempo de trabajo y su distribución}

En cuanto a la duración y distribución del tiempo de trabajo los cambios más importantes fueron: - Se privilegió el cómputo semanal de la duración máxima del tiempo de trabajo, permitiendo una mayor discrecionalidad en la determinación del tiempo diario. trabajadores.

- Se derogaron regímenes especiales establecidos para ciertas categorías profesionales de 
- Se derogó el llamado "sábado inglés", consistente en el cierre del comercio minorista a las 13:00 horas de los días sábado.

- Se ampliaron las excepciones al derecho al descanso en los días domingo y de feriado legal, especialmente respecto del trabajo en establecimientos comerciales y de servicios de atención directa al público, y en las empresas en que se establezcan tales excepciones mediante convenios o contratos colectivos o en fallos arbitrales.

- Se reemplazó la normatividad sobre la extensión de la duración del feriado, especialmente al establecerse: (i) que sólo se computarían los años trabajados para un mismo empleador; (ii) que se debería excluir el tiempo trabajado en el sector público; (iii) que los días adicionales de feriado anual eran susceptibles de negociación individual o colectiva (disponibilidad del derecho); (iv) que el feriado no podía exceder 35 días, incluyendo los inhábiles, y (v) que las partes podían convenir el fraccionamiento de las vacaciones que excedan de 10 días hábiles seguidos. De otra parte, se derogaron las normas sobre feriados de mayor duración para los trabajadores que laboran en las regiones extremas del país o en yacimientos mineros y plantas de beneficio.

- Se permitió pactar tiempos de trabajo de hasta dos semanas consecutivas en lugares apartados de centros urbanos.

- Se facultó al Director del Trabajo para autorizar la fijación de sistemas especiales de distribución del tiempo de trabajo y de los descansos.

\section{Seguridad y salud en el trabajo}

Otras instituciones laborales, como la referida a la prevención y atención de los accidentes del trabajo y las enfermedades profesionales, se conservaron dentro de los parámetros fijados en la reforma establecida en 1968, mediante la ley 16.744, aunque el protagonismo de sus operadores giró desde las entidades públicas de previsión social de esa época, a las mutuales privadas también establecidas en dicha ley. Al establecerse el nuevo sistema de pensiones (Decretos Leyes núms. 3.500 y 3.501 (ambos del año 1980), las responsabilidades subsistentes del Servicio de Seguro Social y de las Cajas de Previsión fueron trasladadas al Instituto de Normalización Previsional (INP), sucesor legal de las mencionadas instituciones de previsión social, las que -junto con el Servicio Nacional de Salud y las Mutualidades de Empleadores- estaban a cargo de la administración del seguro social obligatorio de accidentes del trabajo y enfermedades profesionales, según lo disponía el artículo 8 de la ley 16.744. En la actualidad, las funciones del INP radican en el Instituto de Previsión Social (IPS).

\section{Terminación de la relación de trabajo}

La nueva normatividad modificó substancialmente la regulación preexistente acerca de la terminación colectiva e individual de la relación de trabajo.

Tratándose de la terminación colectiva, se derogó la normatividad anterior que exigía autorización previa ministerial para proceder a toda paralización de actividades o despido de más de 10 trabajadores dentro de un mismo mes calendario. En esa legislación se establecían los requisitos y procedimientos que debían ser observados, se fijaban indemnizaciones y sanciones y se regulaba lo concerniente a la administración de las empresas correspondientes, en los casos contemplados en la legislación.

En cuanto a la terminación individual de la relación de trabajo, la nueva normatividad derogó la legislación referida a las causales de la terminación, los procedimientos, los recursos 
Emilio Morgado Valenzuela / Perspectivas del derecho individual del trabajo

contra la terminación injustificada y las indemnizaciones y sanciones. Los principales cambios fueron los siguientes:

- Se restableció -sin condiciones- la terminación ad nutum, esto es, la que ocurre sin expresión de causa que la motive, bastando el aviso previo al trabajador o - a falta de éste- el pago de una indemnización compensatoria, a elección del empleador.

- Se incorporaron causales que tenían un carácter político, mayormente referidas a la seguridad pública. Tal es el caso de las causales fundadas en la comisión de actos ilícitos que impidan al trabajador concurrir a su trabajo o cumplir con sus obligaciones laborales, o en la comisión de delitos sancionados en las leyes sobre Seguridad Interior del Estado o sobre Control de Armas.

- Se cambiaron los procedimientos para el despido, especialmente cuando se invoca el desahucio patronal, la conclusión del trabajo o servicio, el caso fortuito o la caducidad.

- Se reformó lo concerniente al "despido indirecto" (el que opera cuando es el empleador el que incurre en alguna causal de terminación).

- Se modificó lo atinente al "fuero sindical", que pasó a denominarse "fuero laboral".

- Se establecieron nuevas condiciones y tope máximo para el pago de los gastos de traslado una vez terminado el contrato.

- Se modificó el régimen indemnizaciones y sanciones, disminuyendo el costo del despido.

\section{EL PRESENTE: LA RE-REGULACIÓN PROTECCIONISTA (DESDE EL 11 DE MARZO DE 1990 HASTA HOY)}

La re-regulación proteccionista se inició en Marzo de 1990 y continúa hasta ahora. Se manifestó con fuerza durante los Gobiernos de la Concertación por la Democracia, presididos por Patricio Aylwin Azócar, Eduardo Frei Ruiz-Tagle, Ricardo Lagos Escobar y Michelle Bachelet Jeria. Estuvo presente durante el gobierno de la Alianza por el Cambio, presidido por Sebastián Piñera Echeni$q^{2} e^{2}$. Preside los contenidos laborales y de seguridad social del Programa de Gobierno de la Nueva Mayoría, encabezada por la Presidenta Michelle Bachelet Jeria.

El proceso re-regulador comprende múltiples aspectos de las relaciones individuales de trabajo. Focalizaré mi análisis en los ámbitos temáticos seleccionados en la visión del pasado que precede a estas líneas, esto es: (i) la existencia y características de la relación de trabajo; (ii) el tiempo de trabajo y su distribución; (iii) la seguridad y salud en el trabajo, y (iv) la terminación de la relación de trabajo.

\section{A. Existencia y caracteristicas de la relación de trabajo}

Con el objeto de limitar la "deslaboralización" de relaciones que en realidad son laborales:

- Se sancionó con multa al empleador que dolosamente simula la contratación de trabajadores por terceros, obligándolo a pagar todas las prestaciones laborales de esos trabajadores.

- Se dispuso que las infracciones en la aplicación de las definiciones de los conceptos de trabajador, trabajador independiente, empleador y empresa, dan lugar a la imposición de las sancio-

\footnotetext{
2 No obstante lo anunciado durante su campaña presidencial, en su gobierno no se materializaron las medidas de derogación de numerosos aspectos de la legislación de trabajo y seguridad social adoptada entre 1990 y 2010 . En cambio, la orientación rereguladora proteccionista prima en las leyes adoptadas en materias referidas a ciertos aspectos de las relaciones individuales de trabajo y de la seguridad social.
} 
nes establecidas en los casos de simulación contractual o de evasión o elusión del cumplimiento de obligaciones laborales y previsionales, reguladas en las reformas legislativas de 2001, 2006 y 2008.

- Se estableció el supuesto de multiplicidad de razones sociales consideradas un solo empleador, y sus efectos. (Reforma de julio de 2014).

Se incorporó al campo de aplicación del Código del Trabajo a los trabajadores que laboran en los oficios de notarías, archiveros y conservadores (entidades auxiliares de la administración de justicia).

- Se estableció que las normas del Código del Trabajo se aplicarán a los trabajadores independientes en los casos en que expresamente se refieran a ellos.

- Se ampliaron los contenidos temáticos de los reglamentos internos, especialmente en lo concerniente a la aplicación de sanciones, el acoso sexual y los procedimientos de información a los trabajadores y a sus representantes, incluyendo los sindicatos (Reformas de 2001, 2005, 2009)

- Se revisaron diversos aspectos referidos a las remuneraciones. La reforma más reciente se refiera a la propina en restaurantes, bares, pubs, clubes, discotecas y otros establecimientos similares. (2014).

Mediante legislación adoptada en los años 1998, 2000, 2001, 2002, 2005 y 2009, la tutela de la dignidad de la persona fue ampliada:

- Al establecerse que los actos de discriminación son contrarios a los principios de las leyes laborales.

- Al incorporarse el acoso sexual entre las conductas contrarias a ellas, y establecerse que la práctica de esa conducta es causal de terminación de la relación de trabajo, estableciendo procedimientos para investigar y sancionar dicho acoso (Reforma de 2004).

- Al disponerse que el ejercicio de las facultades que la ley reconoce al empleador tiene como límite el respeto a las garantías constitucionales de los trabajadores, en especial cuando pudieran afectar la intimidad, la vida privada o la honra de estos.

- Al sancionarse el acoso laboral, calificado como contrario a la dignidad de la persona. (Reforma de 2012).

Para limitar las formas precarias de contratación:

- Se redujeron los plazos en que el empleador puede hacer constar por escrito las contrataciones por obra, trabajo o servicio determinado, asi como las contrataciones por plazos inferiores a 30 días.

- Se redujo a un año la duración máxima de los contratos de plazo determinado. A la vez, se mantuvo en dos años la duración máxima de los contratos de trabajo de los gerentes y trabajadores con título profesional o técnico.

- Se dispuso que si el trabajador continúa prestando servicios -con conocimiento del empleador- una vez concluido el plazo, el contrato de plazo fijo se transforma en uno de duración indeterminada. Igual efecto se produce con ocasión de la segunda renovación de un contrato de plazo fijo.

- Se reguló el trabajo a tiempo parcial, esto es, la jornada convenida con una duración no superior a los 2/3 de la jornada ordinaria, con todos los derechos establecidos para los trabajadores a tiempo completo, calculados proporcionalmente al tiempo convenido (Reformas de $1991 \mathrm{y}$ 2001).

En cuanto a la capacidad para contratar y el trabajo de menores, cabe destacar que en 1999 fue ratificado el Convenio $\mathrm{N}^{\circ} 138$ de la OIT, sobre la edad mínima de admisión al empleo, y el Convenio $N^{\circ} 182$ de la OIT, sobre la prohibición de las peores formas de trabajo infantil, cuyas re- 
Emilio Morgado Valenzuela / Perspectivas del derecho individual del trabajo

gulaciones han fundamentado las reformas adoptadas en los años 1999, 2005 y 2007 en lo atinente a labores asignadas a menores en cuanto sean peligrosas para su salud, seguridad o moralidad.

Asimismo, se establecieron normas que tienden a evitar la discriminación por género, derogando prohibiciones como la del trabajo de las mujeres en labores mineras subterráneas.

Para incorporar o mejorar la protección de ciertas categorías de trabajadores, se establecieron regímenes y contratos especiales de trabajo aplicables a:

- Los trabajadores agrícolas en faenas transitorias o de temporada (naturaleza laboral de la relación, contratación escrita, alojamiento y alimentación).

- La gente de mar (requisitos necesarios para alterar sus funciones).

- Los trabajadores portuarios eventuales (definición y regulación de los convenios de provisión de puestos de trabajo).

- Los trabajadores de artes y espectáculos.

- Los deportistas profesionales y trabajadores que desempeñan actividades conexas.

- Los tripulantes de vuelo y de cabina de aeronaves comerciales de pasajeros y carga.

- El trabajo en régimen de subcontratación y trabajo en empresas de servicios transitorios. En relación con esta última normativa, cabe destacar que la ley $\mathrm{N}^{\circ} 20.123$ (2006) puso fin al libre recurso a variadas y no reguladas modalidades de externalización de la relación de trabajo, que daban ilimitada cabida a formas contractuales de "empresas sin trabajadores" y de "trabajadores sin empleador" (Reformas de 2000, 2001, 2003, 2004, 2005, 2006, 2007, 2008, 2009).

Se incentivó la modalidad de pre-contratación permitiendo al eventual empleador descontar de su impuesto a la renta los gastos efectuados en la capacitación de eventuales trabajadores (Reforma de 2010).

\section{B. Tiempo de trabajo y su distribución}

- Se redujo la duración semanal de la jornada ordinaria de trabajo de 48 a 45 horas. (Reforma de 2001, vigente desde 2005).

- Se reguló el establecimiento de sistemas excepcionales de distribución de jornadas de trabajo y descansos - previo acuerdo de los trabajadores involucrados- atendidas las especiales características de la prestación de servicios, siempre que las condiciones de higiene y seguridad sean compatibles con dichos sistemas excepcionales (Reforma de 2001).

- Se establecieron condiciones restrictivas respecto del tiempo de trabajo en hoteles, restaurantes y clubes, así como un procedimiento administrativo para procesar reclamaciones, a la vez que un procedimiento judicial sumario para atender los recursos deducidos en contra de las correspondientes resoluciones de la Dirección del Trabajo (Reformas de 1991 y 2001).

- Se estableció un régimen especial de descanso mínimo que modifica la condición de excluidos de la limitación de la jornada de trabajo de los trabajadores en naves pesqueras (Reformas de 1991 y 2007).

- Se estableció un régimen de jornada ordinaria de trabajo y de descansos para el personal de choferes y auxiliares de la locomoción colectiva interurbana, de servicios interurbanos de transporte de pasajeros y del que se realiza a bordo de ferrocarriles así como de los choferes de vehículos de carga terrestre interurbana y en el servicio de transportes urbanos y rurales de pasajeros (Reformas de 1991, 2001, 2008 y 2014).

- Se permitió pactar cambios en la distribución del tiempo de trabajo en casos en que exista un día hábil entre dos feriados o entre un día feriado y un sábado o domingo (Reforma de 2003). 
- Se dispuso que las horas extraordinarias sólo podrán pactarse para atender necesidades o situaciones temporales de la empresa y que el pacto escrito tendrá una vigencia transitoria no superior a tres meses, pudiendo renovarse por acuerdo de las partes (Reforma de 2001).

- Se prohíbe todo trabajo nocturno de menores de 18 años en establecimientos comerciales o industriales (Reforma de 2011).

- En lo atinente a los "descansos y feriados":

- Se modificó lo relacionado con el descanso semanal compensatorio en las empresas exceptuadas del descanso en días domingo y festivos, fijando sus horas de comienzo y de término.

- Se dispuso que en los establecimientos de comercio y de servicios que atienden directamente al público, el descanso semanal debe otorgarse, por lo menos, en un día domingo al mes.

- Se incorporaron todas las remuneraciones diarias para el efecto de determinar la remuneración de los días domingo y festivos (Reformas de 1991, 1996, 2001, 2003, 2004, 2007, 2008).

- Se amplió el número de días feriado y las regulaciones referidas a los feriados (Reformas de 1996, 2001, 2003, 2004, 2007).

- Se modificó lo relacionado con la acumulación de feriados anuales, el cómputo de la remuneración de los que perciben ingresos variables, el cómputo de los días inhábiles y la duración del feriado progresivo mediante la incorporación del tiempo trabajado para otros empleadores (Reformas de 1991, 1999, 2005, 2006, 2007).

- Se aclaró que la remuneración íntegra durante el feriado deberá incluir la remuneración en dinero por los días domingo y festivos del trabajador remunerado exclusivamente por día, o por el trabajador remunerado por sueldo mensual y remuneraciones variables (Reforma de 2012).

\section{Seguridad y salud en el trabajo}

- Se incorporaron numerosas e importantes modificaciones en lo que concierne a las obligaciones del empleador para proteger eficazmente la vida y salud de los trabajadores, informar de los posibles riesgos, mantener las condiciones adecuadas de higiene y seguridad en las faenas y prevenir accidentes y enfermedades profesionales (Reformas de 1996, 2006, 2007, 2008).

- Se adoptaron normas especiales referidas a las manipulaciones manuales asociadas a la carga, que impliquen riesgos a la salud o a las condiciones físicas de los trabajadores (Reforma de 2005).

- Se ratificó el Convenio 187 de la OIT, sobre el marco promocional para la seguridad y salud en el trabajo, de 2006 (2011).

- Se creó la Intendencia de Seguridad y Salud en el Trabajo (2013).

\section{Terminación de la relación de trabajo}

- La reforma más importante en esta materia fue la derogación de las normas que permitían el despido "ad nutum", esto es, sin expresión de la causa en que se fundamenta. Se retornó así el régimen de despido causado que contribuye a la estabilidad relativa en el empleo. No obstante, el despido "ad nutum" subsiste sólo respecto de quienes trabajan en casa particular (a quienes se protege con una indemnización, cualquiera sea la causa de la terminación de la relación de trabajo), y de los que tienen poder para representar al empleador, como los gerentes, subgerentes y apoderados, siempre que estén dotados de facultades generales de administración.

- Se derogaron las causales de terminación fundadas en motivaciones políticas y policiales, como las vinculadas a la ley de Seguridad Interior del Estado (Reforma de 1990). 
- Se elevó de 5 a 11 años el tiempo que se considera para el pago de la indemnización por años de servicios de los contratados con posterioridad al 14 de agosto de 1981.

- Se facultó a las partes convenir un sistema de indemnización "a todo evento", esto es, cualquiera sea la causa del despido, manteniéndose el derecho a la indemnización de un mes por año de servicio por los primeros seis años trabajados.

- Se amplió el concepto de "última remuneración mensual" para el cálculo y pago de las indemnizaciones, incorporando las contribuciones previsionales de cargo del trabajador (Reforma de 1990).

- Se aumentó en $20 \%$ las indemnizaciones cuando judicialmente se declara que la terminación ha sido injustificada, indebida o improcedente o cuando ella no se ha fundamentado en alguna causal legal, a la vez que se amplió el plazo para que el trabajador reclame contra el despido (Reforma de 1990).

- Se estableció que la invalidez total o parcial no es justa causa para la terminación del contrato de trabajo. La infracción de esta norma es sancionada con el pago de una indemnización especial (Reforma de 2001).

- Se dispuso (en forma no taxativa) que -tratándose de la causal de terminación por necesidades de la empresa, establecimiento o servicio- esas necesidades pueden derivarse de la racionalización o modernización de la empresa, las bajas en la productividad, los cambios en las condiciones del mercado o de la economía que hagan necesaria la terminación de la relación de trabajo (Reformas de 1990 y 2001).

- Se establecieron nuevas normas de procedimiento y de pago de indemnizaciones, que ampliaron la protección ante la terminación de la relación de trabajo. (Reformas de 1999, 2001, $2005,2006,2007$ y 2008), y se fortaleció la protección de los trabajadores con "fuero laboral" (Reforma de 1990).

- Se modificaron los requisitos para acceder al seguro de desempleo (Reforma de 2010).

- Se estableció que el finiquito deberá ser otorgado por el empleador y puesto su pago a disposición del trabajador dentro de diez hábiles, contados desde la separación del trabajador. Las partes podrán pactar el pago en cuotas (Reforma de 2013).

\section{EL FUTURO PREVISIBLE}

\subsection{CONSIDERACIONES PREVIAS}

Reflexionar acerca del futuro del derecho individual del trabajo en Chile nos conduce a formular tres observaciones preliminares:

1. Todo análisis del derecho individual del trabajo requiere reconocer que sus normas no pueden ser debidamente apreciadas si no se tiene presente lo referido a los otros componentes normativos e institucionales del Derecho del Trabajo: las relaciones colectivas de trabajo y su regulación, el sistema laboral procesal y su implementación, y la administración del trabajo y sus proyecciones. Entre todos estos componentes .y al interior de los institutos propios de cada uno de ellos- existen interacciones e influencias recíprocas que condicionan la eficacia y eficiencia de cada una de estas ramas de nuestro Derecho del Trabajo, en lo concerniente a la legislación y la práctica. 
2. A lo anterior debe agregarse que en esos análisis se debe tener presente las interacciones y recíprocas influencias del Derecho del Trabajo y la Seguridad Social.

3. En tales análisis se debe considerar lo que se refiere a los correspondientes contextos políticos y económicos, actuales y previsibles. Incursionar en la futurología en materia de relaciones individual de trabajo presenta varios peligros. Uno de ellos consiste en atribuir niveles de certidumbre casi dogmática a lo que cada analista especializado prefiere y desea asigna prioridad, lo que configura el llamado "wishful thinking".

\subsection{Pronóstico PROSPECTIVO}

Para evitar la tendencia a preferir el "wishful thinking", resulta recomendable recurrir al estudio de las políticas laborales ya anunciadas en el Programa de Gobierno ("Chile de Todos"), presentado por la Presidenta Michelle Bachelet durante su reciente campaña electoral.

Desde ese punto de vista, es posible sostener que -en el corto y mediano plazo- es muy probable que los cambios futuros del derecho individual del trabajo se concentrarán principalmente en los siguientes temas:

La existencia de la relación individual de trabajo y las medidas para evitar y sancionar la deslaboralización de lo laboral.

La promoción de relaciones individuales de trabajo no precarias, adecuadamente remuneradas y protegidas, a la vez que armónicas con las necesidades de aumentar la calidad y productividad necesarias para la competitividad.

El fortalecimiento de la administración pública de trabajo que garantice el efectivo cumplimiento de la legislación laboral.

La vinculación apropiada del derecho individual del trabajo con las políticas públicas de inclusión social y de superación de la pobreza, particularmente en lo que se refiere al salario mínimo y las políticas pro-empleo formal y con mayor participación femenina.

La revisión de la institucionalidad y de los programas de capacitación, formación y readaptación profesionales.

La re-regulación de las normas referidas a: (i) los trabajadores que laboran en actividades agrícolas, particularmente en las de temporada; (ii) las trabajadoras y trabajadores del hogar.

El impulso a la formulación e implementación de una política nacional de seguridad y salud en el trabajo. 